\title{
Experiences of trauma, depression, anxiety, and stress in western-Canadian HEMS personnel
}

\author{
Sebastian Harenberg, ${ }^{*}$ Michelle C.E. McCarron, ${ }^{\dagger}$ R. Nicholas Carleton, ${ }^{\ddagger}$ \\ Thomas O'Malley, \& Terry Ross*
}

\begin{abstract}
Mental health in first responders and other public safety personnel has received substantial research attention in the past decade. Emergency medical services (EMS) demonstrate a heightened prevalence of maladaptive mental health concerns compared to other first responders (e.g., police, fire fighters). Interestingly, there is an absence of research examining helicopter emergency medical services (HEMS) personnel, who respond to what are often life-threatening cases in challenging circumstances. Hence, the purpose of the present study was to assess the experiences of Posttraumatic Stress Disorder (PTSD) and associated mental health conditions (i.e., depression, anxiety, stress) in HEMS workers. HEMS workers from a single mid-western Canadian organization $(n=100)$ participated in the study. The participants completed the Posttraumatic Stress Disorder Checklist (PCL-5) and the Depression, Anxiety and Stress Scale (DASS-21) as part of an online survey. The results revealed that five per cent of HEMS personnel experienced heightened PTSD symptoms. Few participants exhibited signs of mild to severe depression, anxiety, and stress $(<17 \%)$. HEMS personnel experienced fewer mental health concerns than other first responder groups as reported in the literature; indeed, these figures are similar to levels observed within the general population. These findings may be explained by organizational or personality characteristics. Underreporting of mental health concerns may be an alternate explanation. Future qualitative and quantitative research is needed to explain and replicate the results of the present study.
\end{abstract}

Key Words Mental health; first responders; helicopter emergency medical services; PTSD

Journal of CSWB. 2018 Oct;3(2):18-21

www.journalcswb.ca

\section{INTRODUCTION}

First responders and other public safety personnel (PSP) are among those at the highest risk for developing post-traumatic stress disorder (PTSD). In a recent nationwide survey of Canadian public safety personnel, Carleton, Afifi, Turner et al. (2017) found that nearly half $(49.1 \%)$ of the 311 paramedics surveyed screened positive for and/or self-reported the presence of a mental health disorder (e.g., PTSD, major depression, anxiety disorders, alcohol abuse) with nearly one quarter $(24.5 \%, \mathrm{n}=190)$ screening positive for PTSD. Similarly, Wilson, Guiliani, and Boichev (2016) reported lifetime PTSD prevalence rates of 26 per cent for Canadian paramedics. Persons diagnosed with PTSD suffer persistent symptoms such as intrusive and recurring thoughts about the traumatic experience, nightmares, hypersensitivity, and avoidance of stimuli associated with the trauma (American Psychiatric Association, 2013). Symptoms must be present for at least one month and impede functional abilities (e.g., vocationally, socially, emotionally).
Tasked with attending calls involving critical injuries, deaths, and/or violence, first responders, such as paramedics and helicopter emergency medical services (HEMS) personnel, are often confronted with disturbing experiences and imagery in the course of their work. First responders and other PSP may also experience negative effects through secondary exposure to trauma (i.e., hearing details of others' traumatic experiences), resulting in compassion fatigue, secondary PTSD, or vicarious trauma (Cieslak, Shoji, Douglas et al., 2014). There is a growing body of evidence for experiences of trauma and associated PTSD in Emergency Medical Services (EMS) workers; however, we are not aware of any reports relating to the experiences of HEMS personnel.

Typically, HEMS are dispatched to a scene when a case involves high risk of mortality and long distance transport. In addition to caring for the patient, HEMS personnel have to ensure flight safety, deal with longer transportation times from rural and remote locations, and manage increased noise levels that effectively reduce the crew's ability to communicate. The HEMS factors put additional stress on HEMS 
personnel (Cowley \& Durge, 2014). In addition, the images of patients' conditions and the emergency sites may induce additional traumatic stress (Beck, 2011). The present study was designed to assess the prevalence of PTSD and associated mental health conditions (i.e., depression, anxiety, stress) in HEMS workers.

\section{METHODS}

\section{Participants}

In total, $100 \mathrm{HEMS}$ workers $\left(\mathrm{M}_{\text {age }}=42.48, \mathrm{SD}_{\mathrm{Age}}=7.94\right)$ from mid-western Canada participated. Ninety-eight percent of the participants $(\mathrm{n}=98)$ identified their ethnicity as Caucasian. The participants worked in HEMS as nurses $(n=30)$, physicians $(n=20)$, pilots $(n=23)$, and paramedics $(n=27)$. On average, the participants worked 18.41 years $(\mathrm{SD}=8.86)$ in their profession and 7.51 years $(S D=6.76)$ in HEMS.

\section{Procedures and Measures}

The current study was approved by the Regina Qu'Appelle Health Region Research Ethics Board (REB-15-101). HEMS personnel from a single organization were invited to complete an online survey about mental health concerns. The survey was hosted on FluidSurveys (http://fluidsurveys.com/) and distributed via organizational email addresses. The data were collected anonymously. Participants provided descriptive information (e.g., age, gender, job title, years in profession, years in HEMS), and completed scales measuring trauma, depression, anxiety, and stress.

\section{Posttraumatic Stress}

Participants completed the Posttraumatic Stress Disorder Checklist (PCL-5; Bievins, Weathers, Davis et al., 2015) to assess PTSD symptoms corresponding to criteria in the Diagnostic and Statistical Manual of Mental Disorders-5 (DSM-5) (APA, 2013). Items are rated using a Likert-type scale ranging from 0 (not at all) to 4 (extremely). A total severity score (i.e., sum of all items) was used for this study, with a score $\geq$ 33 signifying presence of PTSD symptoms. Initial evidence suggests that the PCL-5 is a psychometrically sound measure with acceptable factorial validity and internal consistency (Bievins et al., 2015). Good internal consistency was also observed in the present study $(\alpha=.94)$.

\section{Depression, Anxiety, Stress}

Participants completed the 21-item version of the Depression Anxiety Stress Scales (DASS-21). Each subscale consists of seven items, which are measured on a 4-point Likert-type scale, ranging from 0 (never) to 3 (almost always). Subscale scores are summed and multiplied by two. Symptom severity ratings were based on recommendations by Lovibond and Lovibond (1995). Previous research has demonstrated acceptable factorial validity and internal consistency for the DASS-21 (Crawford \& Henry, 2003), with good internal consistency observed in the present study ( $\alpha=.81-.92)$.

\section{Statistical Analyses}

Chi-square tests with Fisher's correction were used to conduct comparative analyses of categorical data. For comparative analyses of continuous data, the Mann-Whitney U test with point biserial correlations was calculated when normality was violated. Independent $t$-tests with Cohen's $d$ were used for normally distributed continuous data. For all analyses, a significance level of .05 was set.

\section{RESULTS}

Descriptive statistics are reported in Table 1. The self-reported levels of depression, anxiety, and stress were particularly low. Over 83 per cent of all participants reported normal levels on these variables. Only five (5\%) participants reported a PCL score of 33 or higher (i.e., indicating severe PTSD symptoms). Participants flagged for symptoms consistent with PTSD also reported significantly higher depression $(r=.79, p<.01)$, anxiety $(r=.93, p<.01)$, and stress $(r=.74, p<.01)$; however, there were no significant differences found for age, gender, or years working in the profession, although years working in HEMS approached significance $(p=.09)$. The results of comparative analyses appear in Table 2 . There were no significant differences found on any measured variables between team members (i.e., nurses, physicians, pilots, paramedics).

TABLE I Sample descriptives

\begin{tabular}{|c|c|}
\hline Variable & Mean (SD)/Count (\%) \\
\hline Age & $42.48(7.94)$ \\
\hline Gender & $\begin{array}{c}\text { Male } n=76(76 \%) \\
\text { Female } n=24(24 \%)\end{array}$ \\
\hline Ethnicity & $\begin{array}{l}\text { Caucasian } n=98(98 \%) \\
\text { South East Asian } n=1(1 \%) \\
\text { African American } n=1(1 \%)\end{array}$ \\
\hline Position & $\begin{array}{c}\text { Nurse } n=30(30 \%) \\
\text { Physician } n=20(20 \%) \\
\text { Pilot } n=23(23 \%) \\
\text { Paramedic } n=27(27 \%)\end{array}$ \\
\hline Service in Profession & $18.41(8.86)$ \\
\hline Service in HEMS & $7.51(6.76)$ \\
\hline PCL - PTSD Symptoms & $\begin{array}{c}1.95(.22) \\
<33 n=95(95 \%) \\
>33 n=5(5 \%)\end{array}$ \\
\hline DASS - Depression & $\begin{array}{l}3.03(3.26) \\
\text { Normal }(0-9) n=85(85.9 \%) \\
\text { Mild }(10-13) n=6(6.1 \%) \\
\text { Moderate }(14-20) n=1(1 \%) \\
\text { Severe }(21-27) n=2(2 \%) \\
\text { Extremely Severe }(28+) n=0\end{array}$ \\
\hline DASS - Anxiety & $\begin{array}{l}2.00(1.99) \\
\text { Normal }(0-7) n=89(90.8 \%) \\
\text { Mild }(8-9) n=1 \quad(1 \%) \\
\text { Moderate }(10-14) n=6(6.1 \%) \\
\text { Severe }(15-19) n=1 \quad(1 \%) \\
\text { Extremely Severe }(20+) n=1 \quad(1 \%)\end{array}$ \\
\hline DASS - Stress & $\begin{array}{c}4.49(3.80) \\
\text { Normal }(0-14) n=81 \quad(83.5 \%) \\
\text { Mild }(15-18) n=8(8.2 \%) \\
\text { Moderate }(19-25) n=5(5.2 \%) \\
\text { Severe }(26-33) n=3(3.1 \%) \\
\text { Extremely Severe }(34+) n=0\end{array}$ \\
\hline
\end{tabular}


TABLE II Comparison of groups by PTSD symptoms

\begin{tabular}{lccc}
\hline & $\mathbf{P C L}<\mathbf{3 3}(\mathbf{n = 9 5 )}$ & $\mathbf{P C L}>\mathbf{3 3}(\mathbf{n = 5 )}$ & $\boldsymbol{p}$ \\
\hline Age & $42.37(7.85)$ & $44.60(10.19)$ & n.s. \\
Gender & Male 71 (74.7\%) & Male 3 (60\%) & n.s. \\
& Female 24 & Female 2 & \\
& $(25.3 \%)$ & $(40 \%)$ & \\
Service in Profession & $18.27(8.91)$ & $21.00(8.34)$ & n.s. \\
Service in HEMS & $7.24(6.57)$ & $12.50(9.11)$ & .09 \\
PCL - PTSD & $6.89(6.80)$ & $41.00(5.15)$ & $<.01$ \\
DASS - Depression & $2.73(2.86)$ & $8.60(5.32)$ & $<.01$ \\
DASS - Anxiety & $1.73(1.50)$ & $7.00(3.46)$ & $<.01$ \\
DASS - Stress & $4.15(3.43)$ & $11.00(4.95)$ & $<.01$ \\
\hline
\end{tabular}

\section{DISCUSSION}

The present study was designed to assess the prevalence of trauma, depression, anxiety, and stress in western Canadian HEMS workers. The reported prevalence of PTSD symptoms in the present study is comparable to reports in the general population (i.e., 3.5-6.8\%; Kessler, Berglund, Demier et al., 2005) and substantially lower than previous research in paramedics (i.e., 24.5\%; Carleton et al., 2017). Instead, participants self-reported levels of depression, anxiety, and stress symptoms (i.e., 83-89\% in the "normal" range on the DASS-21) that were particularly low and consistent with reports from the general population (i.e., > 80-94\% normal; Crawford \& Henry, 2003) and some reports from Emergency Medical Service (EMS) personnel (i.e., > 93\% normal; Bentley, Crawford, Wilkins et al., 2013). Taken together, the self-reported symptoms of PTSD, depression, anxiety, and stress were lower in this population than expected.

There are several possible explanations for the current results. EMS workers may experience heightened occupational stress due to performance pressure and a lack of time to debrief (Young \& Cooper, 1995) relative to the present sample. Whereas HEMS workers may see more severe cases, the frequency of missions may be lower, with substantially more time to rest and debrief between missions. Secondly, HEMS personnel might arrive at the scene after some other first responders (e.g., police) and may receive some preliminary information that may prepare them for the upcoming mission. Third, the hiring of HEMS personnel is particularly selective. As such, the selected sample may exhibit personality characteristics that provide psychological resiliency. Lastly, the participating organization provides some psychological counselling services to members, which may have been effective in alleviating mental health symptoms.

There is also an important possibility involving potential underreporting of mental health symptoms. Several researchers have suggested that underreporting of symptoms may be common among first responders and other PSP (e.g., police, firefighters, paramedics; Martin, Marchand, Boyer et al., 2009; Perrin, DiGrande, Wheeler et al., 2007). Underreporting may occur if participants fear for their job security or that they will encounter social pressures if diagnosed a mental health disorder (e.g., PTSD; Martin et al., 2009). A few months before the current study was conducted, a paramedic in Western Canada lost a professional license following self-declaration of a diagnosis of PTSD on his renewal application (Warnica, 2015). The case received significant regional news coverage at the time. While the data for the present study were collected using an anonymous online survey tool, the well-publicized case may have affected the responses. Participants may have feared that descriptive information would reveal their identity or may not have trusted that the survey was truly anonymous. As such, participants may have underreported their mental health symptoms.

Several other limitations apply to the current study. First, an online survey design was chosen. Although this provided data suitable for initially estimating prevalence rates, a diagnostic interview approach would have been more definitive and may have provided context for the results. Second, the study used a cross-sectional assessment of mental health indicators, whereas self-reported symptoms are likely to fluctuate over time (Richter \& Berger, 2006). As such, future studies should examine these variables in a longitudinal fashion. Finally, the study employed a convenience sampling approach, which may have created a response bias. Participants with heightened mental health symptoms may not have felt comfortable completing the survey (e.g., because of the fear of re-experiencing traumatic events).

\section{CONCLUSIONS}

The current study provides important additions to the literature on first responders and other PSP, as well as providing directions for future research. To our knowledge, the current results are the first information on mental health among HEMS workers. Generally, the results indicated low levels of mental health concerns relative to other first responder and PSP groups. Future research should attempt to replicate the current results using diagnostic interview and, assuming the mental health concerns remain low, researchers should assess what might be underlying the unexpectedly low symptom levels. Until such research efforts have been undertaken, the results of the current study should be interpreted with caution.

\section{ACKNOWLEDGMENTS}

The authors acknowledge in-kind support for this research received from the Regina Qu'Appelle Health Region (now Saskatchewan Health Authority).

\section{CONFLICT OF INTEREST DISCLOSURES}

R. Nicholas Carleton's research is supported by the Canadian Institutes of Health Research (CIHR) through a New Investigator Award (FRN: 13666). Otherwise, the authors state that there are no other conflicts of interest.

\section{AUTHOR AFFILIATIONS}

*Department of Exercise and Sport Sciences, Ithaca College, Ithaca, NY, USA; 'Saskatchewan Health Authority, Regina, SK; 'Department of Psychology, University of Regina, Regina, SK, Canada.

\section{REFERENCES}

American Psychiatric Association (2013). Diagnostic and Statistical Manual of Mental Disorders (5th ed.). Washington, DC: American Psychiatric Press Inc. 
TRAUMA, DEPRESSION, ANXIETY, AND STRESS IN HEMS, Harenberg et al.

Beck, C. T. (2011). Secondary traumatic stress in nurses: A systematic review. Archives of Psychiatric Nursing, 25, 1-10. doi:10.1016/i. apnu.2010.05.005

Blevins, C. A., Weathers, F. W., Davis, M. T., Witte, T. K., \& Domino, J. L. (2015). The postraumatic stress disorder checklist for DSM-5 (PCL-5): Development and initial psychometric evaluation. Journal of Traumatic Stress, 28, 489-498. doi:10.1002/its.22059

Bentley, M. A., Crawford, J. M., Wilkins, J. R., Fernandez, A. R., \& Studnek, J. R. (2013). An assessment of depression, anxiety, and stress among nationally certified EMS professionals. Prehospital Emergency Care, 17, 330-338. doi:10.3109/10903127.2012.761307

Carleton, R. N., Afifi, T. O., Turner, S., Tailleu, T., Duranceau, S., LeBeuthillier, D. M., Sareen, J., ... Asmundson, G. (2017). Mental disorder symptoms among public safety personnel in Canada [Advanced online publication]. Canadian Journal of Psychiatry, 63. doi:10.1177/0706743717723825

Cieslak, R., Shoji, K., Douglas, A., Melville, E., Luszczynska, A., \& Benight, C. C. (2014). A meta-analysis of the relationship between job burnout and secondary traumatic stress among workers with indirect exposure to trauma. Psychological Services, 11, 75-86. doi:10.1037/a0033798

Cowley, A., \& Durge, N. (2014). The impact of parental accompaniment in paediatric trauma: A helicopter emergency medical service (HEMS) perspective. Scandinavian Journal of Trauma, Resuscitation and Emergency Medicine, 22, 32. doi:10.1186/1757-7241-22-32

Crawford, J. R., \& Henry, J. D. (2003). The Depression Anxiety Stress Scales (DASS): Normative data and latent structure in a large nonclinical sample. British Journal of Clinical Psychology, 42, 111-131. doi:10.1348/014466503321903544

Kessler, R. C., Berglund, P., Demler, O., Jin, R., Merikangas, K. R., \& Walters, E. E. (2005). Lifetime prevalence and age-of-onset distributions of DSM-IV disorders in the National Comorbidity Survey Replication. Archives of General Psychiatry, 62, 593-602. doi:10.1001/archpsyc.62.6.593
Lovibond, S. H. \& Lovibond, P. F. (1995). Manual for the Depression Anxiety Stress Scale (2nd ed.). Syndey, Australia: Psychology Foundation.

Martin, M., Marchand, A., Boyer, R., \& Martin, N. (2009). Predictors of the development of posttraumatic stress disorder among police officers. Journal of Trauma \& Dissociation, 10, 451-468. doi:10.1037/a0038780

Perrin, M. A., DiGrande, L., Wheeler, K., Thorpe, L., Farfel, M., \& Brackbill, R. (2007). Differences in PTSD prevalence and associated risk factors among World Trade Center disaster rescue and recovery workers. American Journal of Psychiatry, 164, 1385-1394. doi:10.1176/appi. ajp.2007.06101645

Richter, D., \& Berger, K. (2006). Post-traumatic stress disorder following patient assaults among staff members of mental health hospitals: A prospective longitudinal study. BMC Psychiatry, 6, 15. doi:10.1186/1471-244X-6-15

Warnica, M. (2015, October 8). Paramedic with PTSD loses job, may lose house after licence dispute. Edmonton, AB: Canadian Broadcasting Corporation (CBC) News. Retrieved from http://www.cbc.ca/news/ canada/edmonton/paramedic-with-ptsd-loses-job-may-lose-house-afterlicence-dispute-1.3261892

Wilson, S., Guliana, H., \& Boichev, G. (2016). On the economics of post traumatic stress disorder among first responders in Canada. Journal of Community Safety \& Well-being, 1. Retrieved from https://journalcswb. $\mathrm{ca} /$ index.php/cswb/article/view/6/30

Young, K. M., \& Cooper, C. L. (1995). Occupational stress in the ambulance service: A diagnostic study. Journal of Managerial Psychology, 10, 29-36. doi:10.1108/09552069710184418 